\title{
The supply of illegal tortoise meat to Toliara City, south-western Madagascar
}

\author{
Theodore Manjoazy, Julie H. Razafimanahaka, William Ronto \\ Roma Randrianavelona, Jörg U. Ganzhorn and Richard K. B. Jenkins
}

\begin{abstract}
A range of endemic and protected vertebrate species from Madagascar are threatened by the demand for bushmeat. We report on the number of discarded carapaces from illegally killed Critically Endangered radiated tortoises Astrochelys radiata in an urban centre in south-west Madagascar. Through covert monitoring of public rubbish dumps we observed 1,913 carapaces during July 2010-January 2014. There was notable spatial and temporal variation, with some evidence of peaks in carapace dumping during May-June and October-December. A single rubbish dump near the artisanal fishery landing beaches accounted for $93 \%$ of the observed carapaces.
\end{abstract}

Keywords Astrochelys radiata, Atsimo-Andrefana, bushmeat, Madagascar, Malagasy, radiated

$\mathrm{M}$ adagascar's four endemic tortoise species are categorized as Critically Endangered on the IUCN Red List (IUCN, 2015), and three are primarily threatened by illegal and unsustainable levels of collection for the international pet trade and to meet the demand for domestic bushmeat (Jenkins et al., 2014). The ongoing seizure of radiated tortoises Astrochelys radiata at transport hubs is evidence of continued international demand for this species, failure of enforcement (Todd, 2011; Chng, 2014), and a breakdown of the traditional taboo that was once thought to protect the species in many parts of its range (Juvik, 1975). The domestic demand for illegal meat from $A$. radiata in parts of southern Madagascar fuels a large proportion of the ongoing illegal harvest, sale and consumption of this tortoise and continues to present a major challenge to the Malagasy authorities, local communities and conservation organizations (O'Brien et al., 2003; Castellano et al., 2013). The species, which is restricted to the spiny dry forests of

Theodore Manjoazy ${ }^{*}$, Julie H. RaZafimanahaKa and Roma Randrianavelona Madagasikara Voakajy, Antananarivo, Madagascar

William Ronto Département de Biologie Animale, Faculté des Sciences, Université d'Antananarivo, Antananarivo, Madagascar

Jörg U. GANZHORN Biocenter Grindel, University of Hamburg, Hamburg, Germany

RichaRd K.B. JENKIns $\dagger$ (Corresponding author) School of the Environment, Natural Resources and Geography, Bangor University, Bangor, Gwynedd, UK E-mail richard.jenkins@iucn.org

*Also at: Faculté des Sciences, Université de Tuléar, Tuléar, Madagascar †Current address: IUCN, The David Attenborough Building, Pembroke Street, Cambridge, CB2 3QZ, UK

Received 22 July 2015. Revision requested 25 August 2015.

Accepted 2 March 2016. First published online 10 February 2017. south-western Madagascar between Morombe and Amboasary, reportedly underwent a $47 \%$ population decline within just 2 years, as well as a major range contraction (Rafeliarisoa et al., 2012; Walker \& Rafeliarisoa, 2012).

Published information on the supply chain of $A$. radiata is fragmented, with many gaps and a general lack of quantitative data. Hunting and trade of protected species in Madagascar is normally a clandestine affair, making it particularly difficult for conservation scientists to obtain reliable, quantitative information on the nature and scope of activities (Razafimanahaka et al., 2012). However, information across the supply chain, from collection sites, through transit localities to consumers, is needed to inform enforcement and conservation activities.

We report here on monitoring of discarded A. radiata carapaces in the urban centre of Toliara, south-western Madagascar. Previous studies have reported that live tortoises and tortoise meat are collected to meet the demand from restaurants in Toliara and Tolagnaro (Fort Dauphin) and that the meat is considered a delicacy and consumed during public holidays and special occasions, such as Christmas (Castellano et al., 2013). During June 2010-January 2014 we conducted covert visits to a number of fokontany (wards) with open-air rubbish dumps in public spaces in Toliara where tortoise carapaces had reportedly been discarded. These sites were selected based on informal discussions and observations made in 2010. All observations were conducted during daylight hours by the same individual (TM), who counted the number of new carapaces of $A$. radiata during each visit. Visits varied in duration and were typically quick when carapace abundance was low, but took much longer, often requiring observation from a number of vantage points, when carapace abundance was relatively high.

Rubbish dumps in six fokontany (Mahavatse I East, Mahavatse I West, Mahavatse I Tanambao, Mahavatse II, Ambohitsabo, and Tanambao Motombato) were visited throughout the study, and three additional fokontany (Anketraka, Toliara Centre and Ankiembe) were visited in 2013 only (Fig. 1). Each dump was visited at least once per month unless water levels were too high, with multiple visits to some sites. Additional visits were needed for a variety of reasons but mainly to maintain secrecy during counts of large carapace dumps. It was possible to distinguish new carapaces because they were fresh in appearance and free of dust and grime. Every effort was made to conduct the observations covertly prior to February 2013. Thereafter, following a change in project rationale and objectives, 


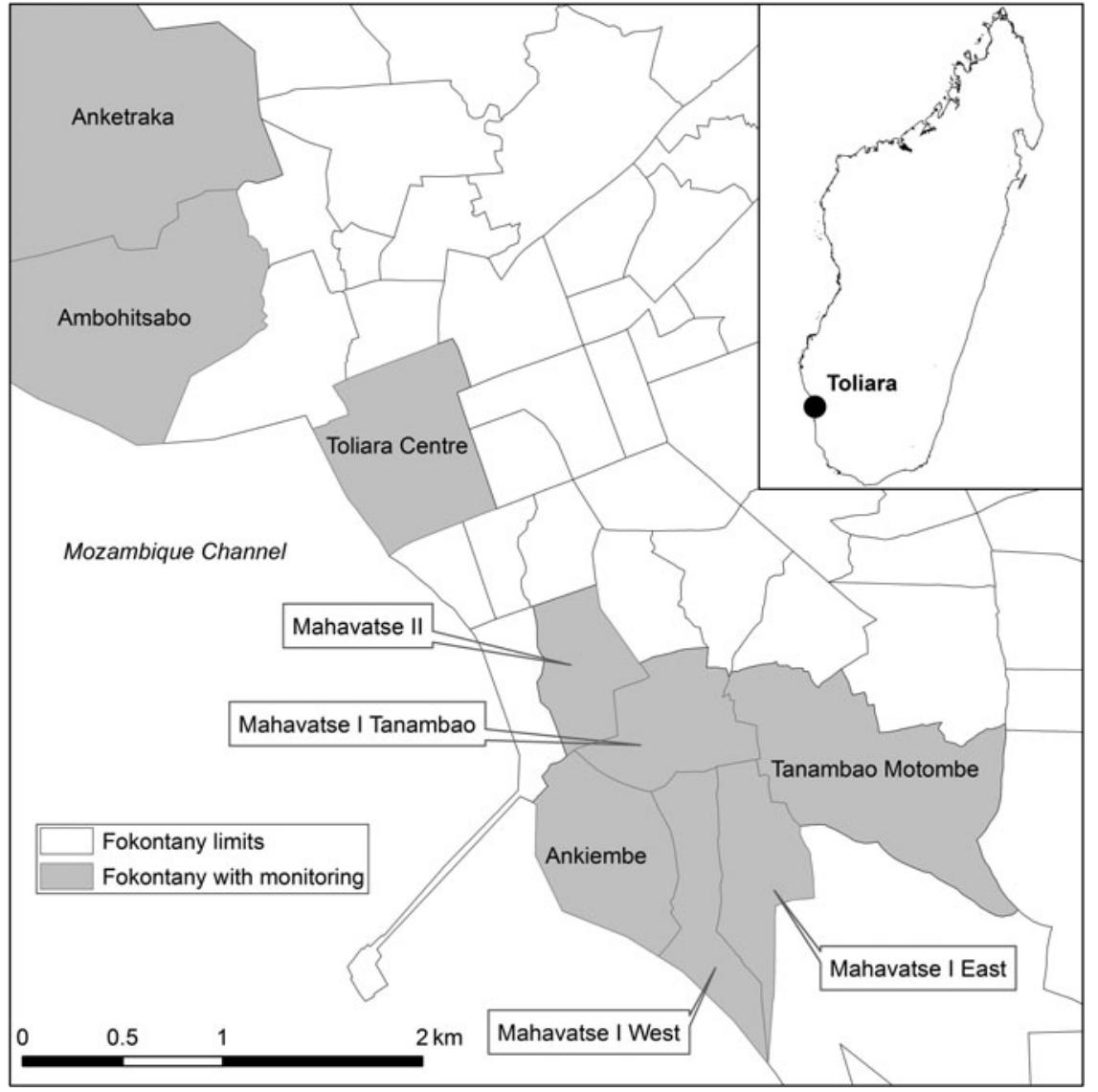

FIG. 1 The study site in Toliara City, Madagascar. carapaces were measured on-site in full view of the public (these data will be published elsewhere). The specific objectives of our study were to obtain quantitative minimum counts of the number of tortoises killed in Toliara for bushmeat and to determine whether peaks in tortoise consumption coincided with major public or religious holidays.

A total of 1,913 carapaces were observed during 216 days of monitoring. Cyclonic activity caused high water levels, which resulted in incomplete data collection during some months. Nevertheless, it appears that the number of discarded tortoise carapaces was higher in 2012 than in the other years of the study (Fig. 1). It also appears that relatively fewer tortoise carapaces were discarded in the austral winter months (June-September), whereas large numbers were discarded in the austral summer (October-February). Peak carapace counts in 2010 and 2011 were in May and November-December. In 2012 the peak carapace count was in May, followed by another peak in October and November. Few tortoise carapaces were observed in 2013, following the peak during January 2013. There is therefore some evidence of peaks in carapace dumping during May-June and October-December. A single rubbish dump at Mahavatse, an area near the artisanal fishery landing beaches, accounted for $93 \%$ of the observed carapaces. Low numbers of carapaces were observed at Anketraka, located to the east of the landing beaches, and there were few observations of carapaces at the two other sites included in 2013.

Estimates of the number of radiated tortoises harvested annually vary from c. 45,000 (O'Brien et al., 2003) to 518,000 (Walker \& Rafeliarisoa, 2012). Although the numbers of carapaces observed in this study represent a relatively small proportion of the estimated annual harvest, the data provide important pointers for future enforcement and conservation efforts in the urban centre of Toliara. The observations support the hypothesis that the delivery of tortoises to Toliara is seasonal, but provide weaker support for linking this to particular events, such as Christmas and public holidays. The rubbish dumps are low-lying and were inundated with floodwater following cyclones during each year of the study, which obscured some of the underlying temporal variation that might have otherwise been more evident. Nevertheless, it is clear that even accounting for interannual variation in supply there are two peaks in any given year that may be related to Independence Day in June and Christmas in December. Seasonal tortoise activity may also significantly influence collection effort and success and contribute to higher consumption during the austral summer, when the species is most active and hence supplies of tortoise meat are greater. Regardless of the reason for these seasonal peaks it would be sensible to focus enforcement and conservation activities in the areas near the artisanal fishery 


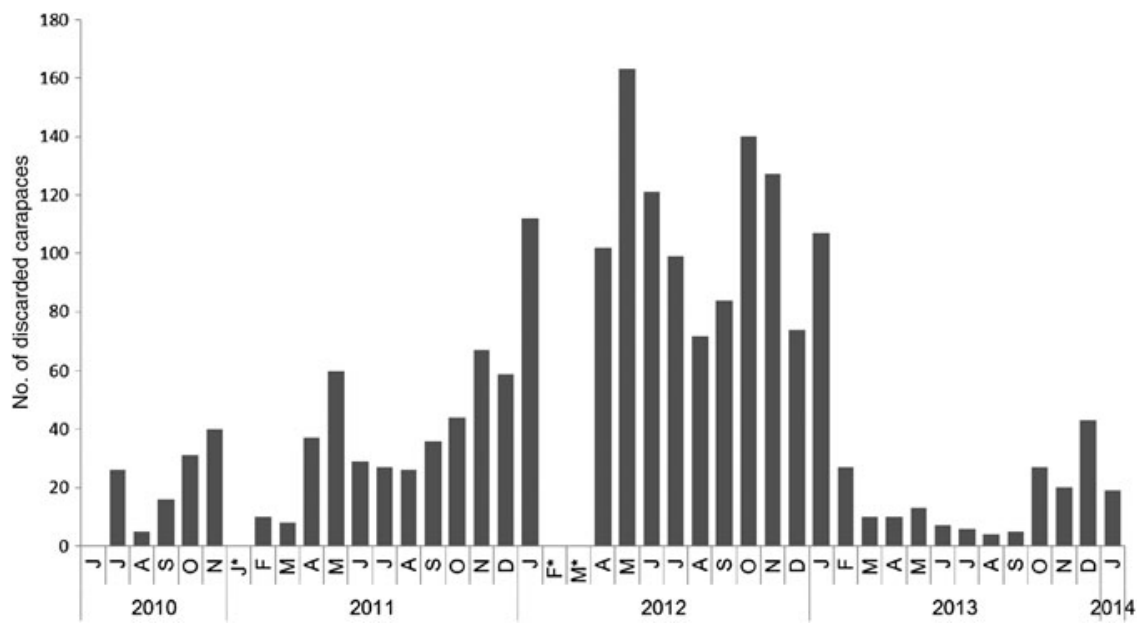

FIG. 2 Number of discarded carapaces of radiated tortoises Astrochelys radiata recorded at rubbish dumps in the urban centre of Toliara, Madagascar, during June 2010-January 2014. Ten dumps were monitored during June 2010December 2012. Another five were included in the study in January 2013. ${ }^{*}$ No survey due to high flood water

landing beaches where carapace dumping was consistently highest, and during the months of May-June and October-December. This should be accompanied by similar activities at the supply end, in the areas from where the tortoises are collected and transported. The decline in the number of observed carapaces in 2013 was probably because the monitoring team became too visible and thus tortoise butchers took more care in disposing of carapaces. It seems that burial became the preferred option ( $\mathrm{T}$. Manjoazy, pers. obs.). Mahavatse remained the main arrival point for tortoise-laden pirogues at night.

A range of activities are needed across the supply chain to combat the illegal harvest of radiated tortoises, including enforcement, demand reduction and community involvement (Hudson, 2013). As A. radiata is a fully protected species under Malagasy wildlife legislation there are currently no options for sustainable, legal and consumptive use (Ganzhorn et al., 2015). Efforts should therefore focus on the protection of wild tortoises through community engagement, awareness raising, and enforcement. These should take place across the supply chain, including communities in the Mahafaly Plateau, people involved in transporting tortoises by sea and land, and human population centres where demand is high. As there is increasing evidence that the demand for tortoise bushmeat extends as far as the capital city, Antananarivo, it is imperative that enforcement activities in urban centres of demand and along major transport routes are intensified and respond to any changes in the behaviour of the tortoise transporters, butchers and purveyors. The results of this study were presented to stakeholders, including local authorities, during a workshop on 12 December 2013. Following this workshop there was a notable increase in reports of tortoise consignments to the local authorities.

\section{Acknowledgements}

Funding for the monitoring was provided by the UK government's Darwin Initiative and the German Ministry for
Education and Research (Sustainable Land Management Programme). We are grateful to the universities of Toliara and Antananarivo for supporting this work, and the government of Madagascar for authorizing the research.

\section{References}

Castellano, C.M., Doody, J.S., Rakotodrainy, R., Ronto, W., Rakotodriamanga, T., Duchene, J. \& Randria, Z. (2013) Long-term monitoring and impacts of human harvest on the radiated tortoise. Chelonian Research Monographs, 6, 75-85.

CHNG, S.C.L. (2014) Seizures of Tortoises and Freshwater Turtles in Thailand 2008-2013. TRAFFIC, Petaling Jaya, Selangor, Malaysia.

Ganzhorn, J.U., Manjoazy, T., Paplow, O., Randrianavelona, R., Razafimanahaka, H.J., Ronto, W.M. et al. (2015) Rights to trade for species conservation: exploring the issue of the radiated tortoise in Madagascar. Environmental Conservation, 42, 291-293.

Hudson, R. (2013) Troubled times for the radiated tortoise (Astrochelys radiata). In Turtles on the Brink in Madagascar: Proceedings of Two Workshops on the Status, Conservation, and Biology of Malagasy Tortoises and Freshwater Turtles (eds C.M. Castellano, A.G. J. Rhodin, M. Ogle, R.A. Mittermeier, H. Randriamahazo, R. Hudson \& R.E. Lewis). Chelonian Research Monographs No. 6.

IUCN (2015) The IUCN Red List of Threatened Species v. 2015-4. Http://www.iucnredlist.org/ [accessed 11 May 2016].

Jenkins, R.K.B., Tognelli, M.F., Bowles, P., Cox, N., Brown, J.L., Chan, L. et al. (2014) Extinction risks and the conservation of Madagascar's reptiles. PLoS ONE, 9(8), e1oo173.

JuviK, J.O. (1975) The radiated tortoise of Madagascar. Oryx, 13, 145-148. O’Brien, S., Emahalala, E.R., Beard, V., Rakotondrainy, R.M., Reid, A., Raharisoa, V. \& Coulson, T. (2003) Decline of the Madagascar radiated tortoise Geochelone radiata due to overexploitation. Oryx, 37, 338-343.

Rafeliarisoa, T.H., Walker, R.C.J. \& Louis, Jr, E.E. (2012) Turtles on the brink in Madagascar: proceedings of two workshops on the status, conservation, and biology of Malagasy tortoises and freshwater turtles (eds C.M. Castellano, A.G.J. Rhodin, M. Ogle, R. A. Mittermeier, H. Randriamahazo, R. Hudson \& R.E. Lewis). Chelonian Research Monographs No. 6.

Razafimanahaka, J.H., Jenkins, R.K.B., Andriafidison, D., Randrianandrianina, F., Rakotomboavonjy, V., Keane, A. \& Jones, J.P.G. (2012) Novel approach for quantifying illegal bushmeat consumption reveals high consumption of protected species in Madagascar. Oryx, 46, 584-592. 
Todd, M. (2011). Trade in Malagasy Reptiles and Amphibians in Thailand. TRAFFIC Southeast Asia, Petaling Jaya, Selangor, Malaysia.

Walker, R.C.J. \& Rafeliarisoa, T.H. (2012) Distribution of radiated tortoise (Astrochelys radiata) bush meat poaching effort. Chelonian Conservation and Biology, 11, 223-226.

\section{Biographical sketches}

Theodore Manjoazy is interested in investigating human-wildlife interactions, and studying the bats of Madagascar. Julie Hanta
RAZAFIMANAHAKA is interested in studying the links between people and nature, and is passionate about fully engaging Malagasy people in biodiversity conservation. WILLIA M RonTO is a zoologist and has worked on aspects of the ecology, hunting and reintroduction of radiated tortoises for several years. ROM A RANDRI ANAVELONA is a conservation biologist whose ambition is to engage local communities and build partnerships for biodiversity conservation in Madagascar. JÖ R G GAN Z H O RN is a zoologist with over 30 years' experience conducting field work in Madagascar. He has published widely on the vertebrate fauna of Madagascar and conservation. RichaRD JENKInS works on global species issues and has been involved in biodiversity conservation in Madagascar for 25 years. 